\title{
O ÚLTIMO ENCONTRO: O PASTOR E SUA AMIGA “CABEÇA DURA”
}

THE LAST MEETING: THE PASTOR AND HIS STUBBORN FRIEND

Nadège Mézié

À memoria de Grann e de pastè Christ-Roi

Resumo: Este ensaio retrata o último encontro entre dois amigos, duas figuras fortes da regiáo onde trabalhei no Haiti, nas montanhas do departamento da Grand'Anse. Ambos de idade, ele evangelista com o dom de cura, ela uma mulher orgulhosa, que nunca se converteu ao protestantismo, apesar de todos os seus filhos e netos terem se convertido. À beira da morte, ela, Grann, o chama para ficar perto dela nesse momento, sem que possamos saber se ela chamava o amigo ou o curador. As fotos mostram diferentes cenas desse encontro, durante o qual pastè Christ-Roi ora, impóe as mãos sobre a doente, lhe faz companhia.

Palavras-chave: Haiti; Cura; Prece; Amizade; Pentecostalismo.

Abstract: This essay depicts the last meeting between two friends, Grann and pastor Christ-Roi, two strong figures from the region where I worked in Haiti, in the mountains of the Grand'Anse department. Both old, he evangelist with the gift of healing, she a proud woman who never converted to protestantism despite the fact that all her children and grandchildren did. On the verge of death, Grann calls him to be near her at this moment, without us knowing if she was calling her friend or the healer. The photos show different scenes of this encounter, during which pastor Christ-Roi prays, imposes his hands on Grann, keeps her company.

Keywords: Haiti; Healing; Christian Prayer; Friendship; Pentecostalism.

1 Faculté de Sciences Humaines et Sociales da Université Paris Descates em Paris, França. E-mail: nadege.mezie@wanadoo.fr.

2 Todas as fotografias são de minha autoria. A primeira imagem data de setembro de 2006 e as demais de dezembro do mesmo ano. Grann e pastè Christ-Roi sabiam que eu as publicaria.

Debates do NER, Porto Alegre, Ano i 9, N. 35, P. 405-4I 4, Jan./Jul. 20 i 9 
Conheci Grann Vierge dois dias depois de ter chegado em Mòn Anvè, um pequeno vilarejo no interior montanhoso do departamento da Grand'Anse, Haiti. Grann significa avó, em crioulo haitiano, e esse termo é utilizado para se dirigir a mulheres idosas em geral. A Grann a que me refiro, no entanto, era conhecida apenas como Grann. Ela era a avó de Olsen, na casa de quem eu ficaria um ano e meio, hospedada por ele e sua esposa, Madan Olsen. Naquele março de 2005, Grann tinha 75 anos de idade e era viúva há mais de vinte. Seus três filhos vivos fazem parte da diáspora haitiana, dois moravam (e moram ainda) na França e uma, na Alemanha. O marido de Grann era um homem que possuía muitas terras e tinha cargos políticos na regiáo, era um gwo nèg como diziam, ou seja, um homem poderoso. Com sua morte, as parcelas de terra foram aos poucos vendidas; dentre elas, um grande terreno foi adquirido por um casal de missionários americanos. Grann ficou com poucos bens, uma casa, seu jarden (pequena roça ao redor da casa) e alguns lotes esparsos. Olsen, o único neto que morava nas montanhas - todos os outros estavam na capital ou no estrangeiro - administrava o que restara das terras.

Durante a minha pesquisa, a casa de Grann e, sobretudo a sua cozinha, era o meu refúgio. Eu ia lá para descansar, para náo falar, para sair da pesquisa. Grann seguia tranquilamente com seus afazeres, em silêncio ou resmungando contra um ou outro dos seus vizinhos, compadres ou parentes. A pesquisadora não tomava conta de mim, que era o que eu precisava de vez em quando. Apesar de ser muito respeitada, Grann era conhecida pelo seu forte e mau temperamento, de 'tèt di (cabeça dura)'. Ela era um das poucas que nunca entrava na missão e que não escondia sua irritação em relação ao que ela chamava de ingratidão da parte dos missionários: "eu vendi minha terra para eles a um preço baratíssimo, porque era para Deus. E eles nunca mais se preocuparam comigo". Sob a insistência dos seus netos, que estiveram entre os primeiros e principais apoiadores da missáo evangélica, ela chegou a ir, no início e algumas poucas vezes, à igreja. Mas nunca aceitou se converter. Todos os netos de Grann que moram no Haiti são evangélicos praticantes e têm um papel de liderança em suas igrejas, fazem a ponte com missionários americanos e canadenses, ou, ainda, são 
pastores. Os que passaram pela Europa ou moram ali, transitam entre a religião baháí e a evangélica, sempre com engajamentos importantes. $\mathrm{Na}$ família, a religião é portanto um assunto de primeira ordem, e esse envolvimento intenso os permite também aceder a ganhos materiais e simbólicos. Já Grann, nunca abandonou práticas de profilaxia contra doenças e açôes malevolentes comuns no Vodu haitiano, que combina dimensões religiosas, mágicas e terapêuticas (Brodwin, 1996; Vonarx, 2012). Ela costumava se vestir de vermelho e usava lençóis dessa cor - o vermelho tem um significado importante no Vodu, sendo, por exemplo, a cor associada aos lwa do rito Petro, espíritos caracterizados pela força, violência e mobilizados nas práticas de feitiçaria. Usava também talismãs e amuletos, pendurados em seu próprio corpo ou dispostos em diversos cantos da casa. Em suas paredes, também ficavam algumas imagens católicas. Os familiares evangélicos diziam que como Grann era Grann, náo era possível arrazoá-la e fazê-la abandonar essas 'coisas do diabo (bagay dyab)'. Grann, em resposta, chamava-os de “evangélicos hipócritas", de "pouca fé".

Em 2006, aos 76 anos, a saúde de Grann deteriorou-se. Suas pernas inchadas indicavam uma insuficiência venosa e cardíaca, segundo o médico da cidade (Okay, para onde ela acabou tendo que ir, levada por Olsen, contra sua vontade). No final do ano, muito enfraquecida, ela foi conduzida ao hospital na cidade. Lá, disseram que o mal não tinha mais remédio e a mandaram de volta para casa. No dia seguinte, com a respiraçáo ofegante, ela me pediu que chamasse o pastor (pastè) Christ-Roi, seu grande amigo de infância, que ela não via há muitos anos. Eu conhecia bem pastè Christ-Roi, já eu que frequentava a igreja pentecostal que ele tinha fundado num vilarejo vizinho.

Com 83 anos de idade, pastè Christ-Roi era conhecido por ter implantado o protestantismo na região, a partir dos anos 1940, em incessantes andanças pelas montanhas. Ele mesmo se converteu, aos vinte anos de idade, depois de um encontro com um missionário evangélico cubano perto da cidade de Jérémie. Desde sua conversão, Christ-Roi dedicou sua vida inteira à pregação e à cura de doentes pela oração. Criou mais de quarenta pequenas igrejas, que ele passava em seguida a pastores locais, sem exigir nenhum tipo de 
subordinação ou reverência. Ele e sua família viviam de muito pouco, das doações (de comida ou algumas moedas) de fiéis ou doentes que ficavam, durante o tratamento, em sua casa. Virtuose da prece, pastè Christ-Roi gozava de um “carisma da fé", para retomar a noção de Max Weber (2004, p. 327), ou seja, ele tinha uma capacidade, tanto espiritual como terapêutica, reconhecida como extraordinária, e esse carisma nunca se desgastou com o tempo. Somente com a velhice, ele deixou de caminhar pelas montanhas e cidades. Talvez um pouco tèt di ele também, pastè Christ-Roi nunca aceitou os convites de sua filha para se estabelecer na cidade (Jérémie), onde ela, casada com um militar estadunidense aposentado, queria que ele administrasse uma igreja e um orfanato por ela fundados. Christ-Roi dizia querer ficar perto dos que realmente precisavam dele.

Durante dois dias, no final de dezembro de 2006, ele ficou na casa de Grann. Com dificuldade de caminhar e quase cego, ele se sentou perto da cama de Grann, onde ela estava deitada desde o retorno do hospital. De noite e de dia, ele rezou, alternando entre gritos e sussurros. Em intervalos regulares, ele batia palmas ou se levantava batendo sua bengala no chão. Aos que visitaram Grann nesses dois dias, e os visitantes foram muitos, ele pedia para ler um verso de tal ou tal livro da Bíblia. De vez em quando, ele lhe impunha as mãos onde ela mostrava ter dor. Poucas palavras foram trocadas entre eles, já que Grann não tinha mais fôlego e força para falar. Ela se abandonou às preces e às mãos do seu amigo. Grann decedeu duas semanas depois que pastè Christ-Roi a deixou, e ele, por sua vez, decederia seis meses mais tarde.

\section{REFERENNCIAS}

BRODWIN, Paul. Medicine and morality in Haiti: the contest for healing power. Cambridge: Cambridge University Press, 1996.

VONARX, Nicolas. Le Vodou haïtien. Entre médecine, magie et religion. Rennes; Laval (Canada): Presses Universitaires de Rennes: Presses Universitaires de Laval, 2012. 
WEBER, Max. Economia e Sociedade. Fundamentos da sociologia compreensiva, v. 2. São Paulo: Editora UnB, 2004.

Fotografia 1 - Grann descansando os pés inchados.

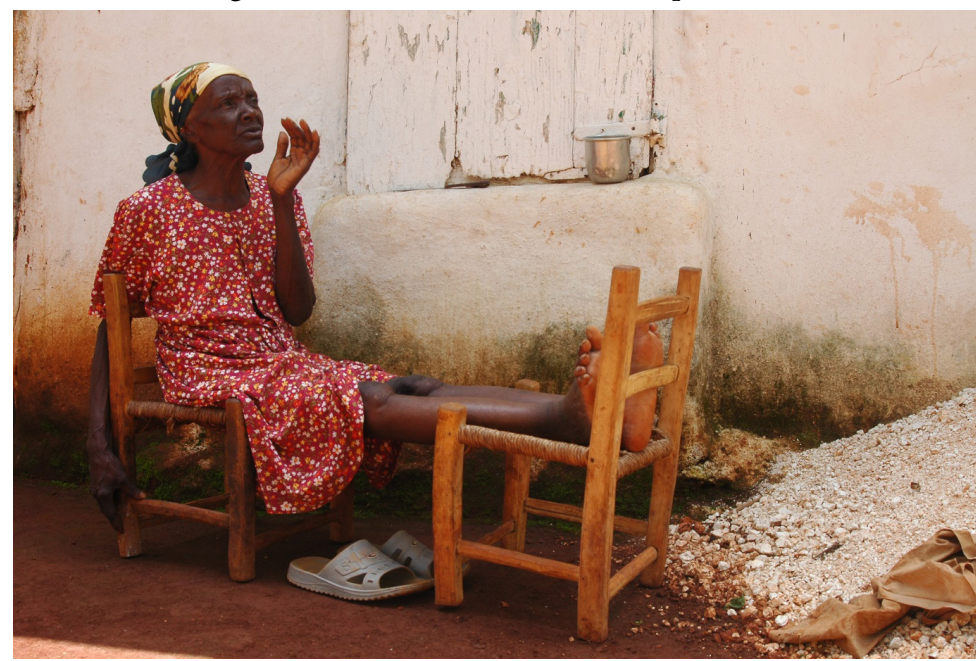

Fonte: Fotografia de minha autoria. Essa primeira imagem data de setembro de 2006. Grann e pastè Christ-Roi sabiam que eu a publicaria. 
Fotografia 2 - Pastè Christ-Roi, Grann e Marlissa

(vizinha que ficou na casa de Grann durante os últimos dois meses de vida de Grann).

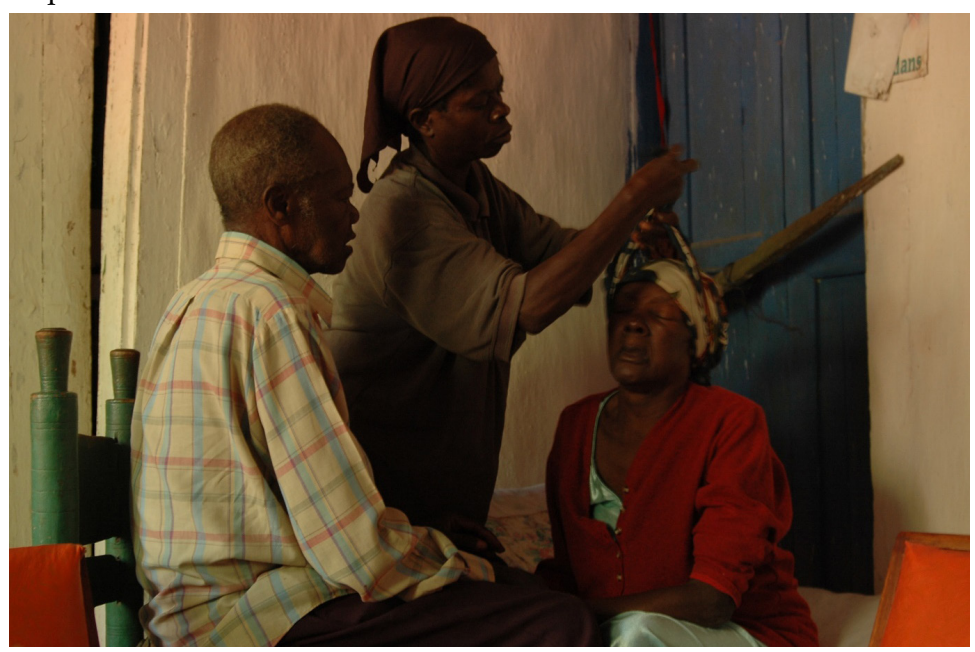

Fonte: Todas as fotografias são de minha autoria. Essa imagem data de dezembro de 2006. Grann e pastè Christ-Roi sabiam que eu a publicaria.

Fotografia 3 - Imposição de mãos I.

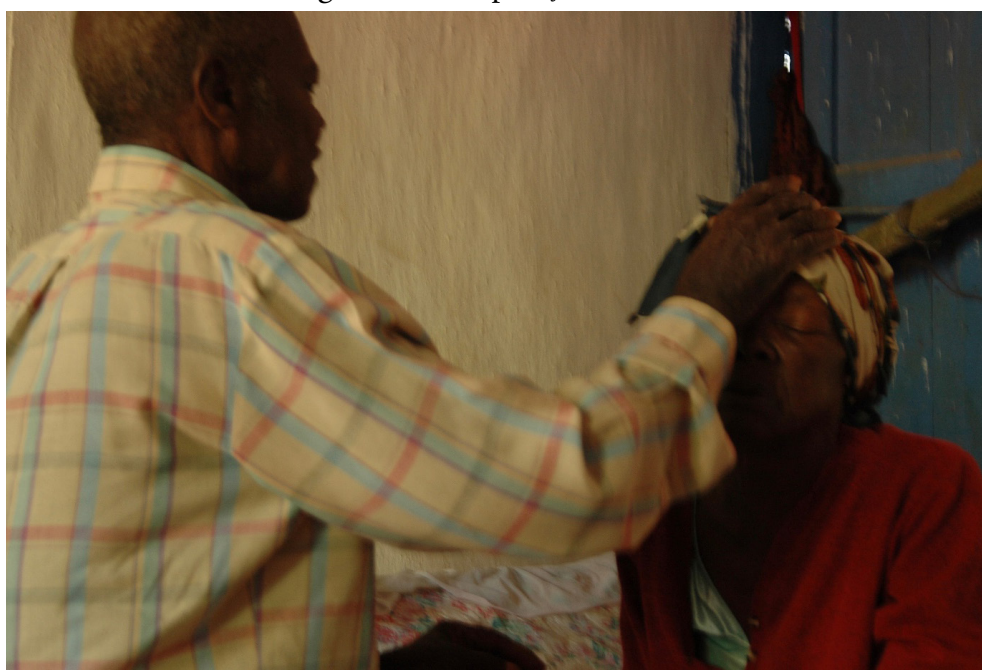

Fonte: Todas as fotografias são de minha autoria. Essa imagem data de dezembro de 2006. Grann e pastè Christ-Roi sabiam que eu a publicaria. 
Fotografia 4 - Imposição de mãos II.

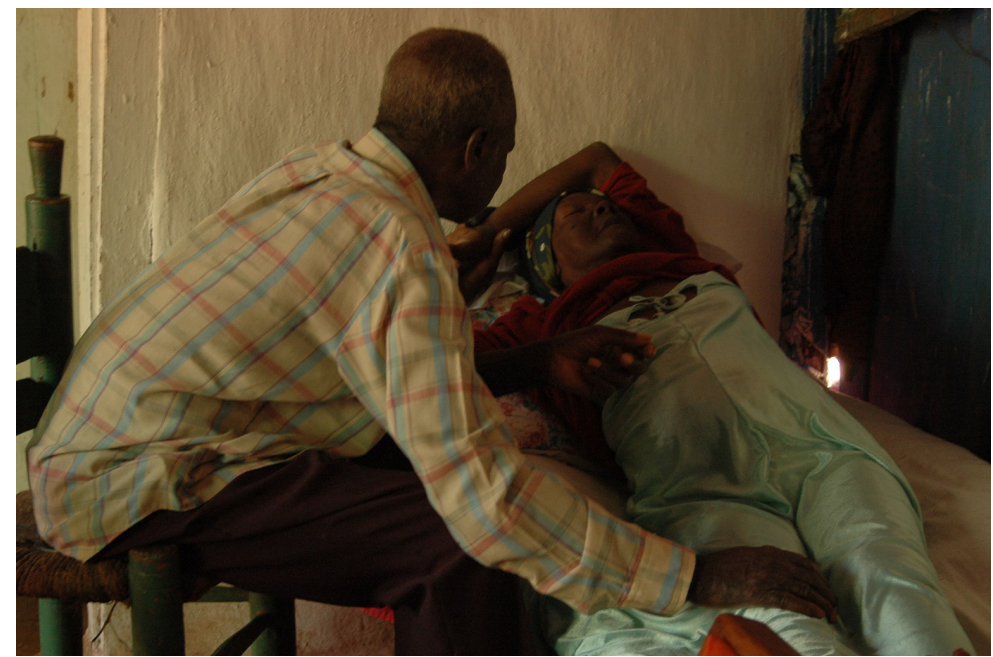

Fonte: Todas as fotografias são de minha autoria. Essa imagem data de dezembro de 2006. Grann e pastè Christ-Roi sabiam que eu a publicaria.

Fotografia 5 - Imposição de mãos III.

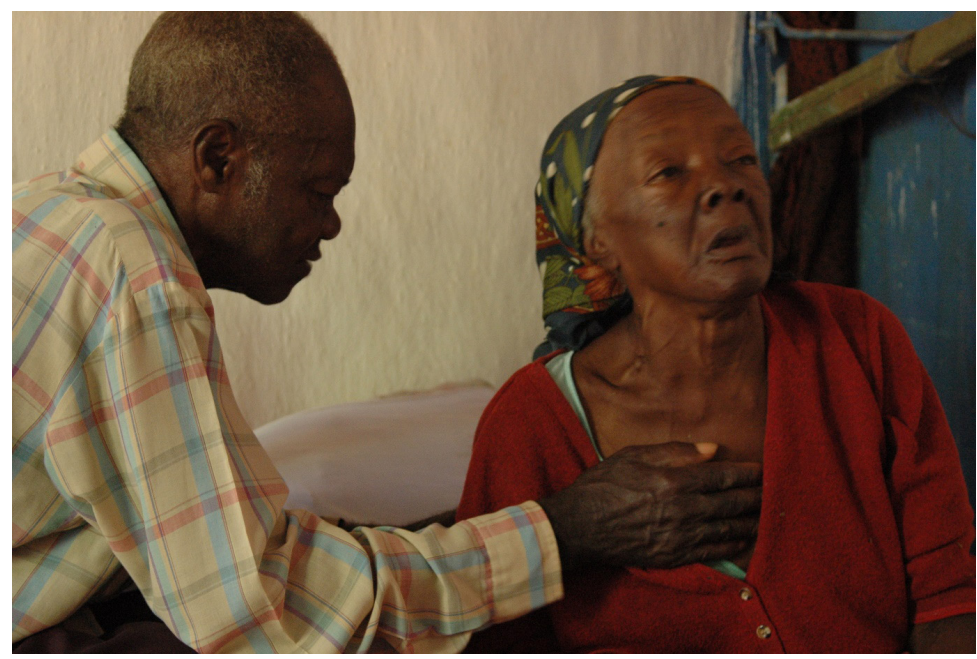

Fonte: Todas as fotografias são de minha autoria. Essa imagem data de dezembro de 2006. Grann e pastè Christ-Roi sabiam que eu a publicaria. 
Fotografia 6 - Pastè Christ-Roi ora e bate palmas.

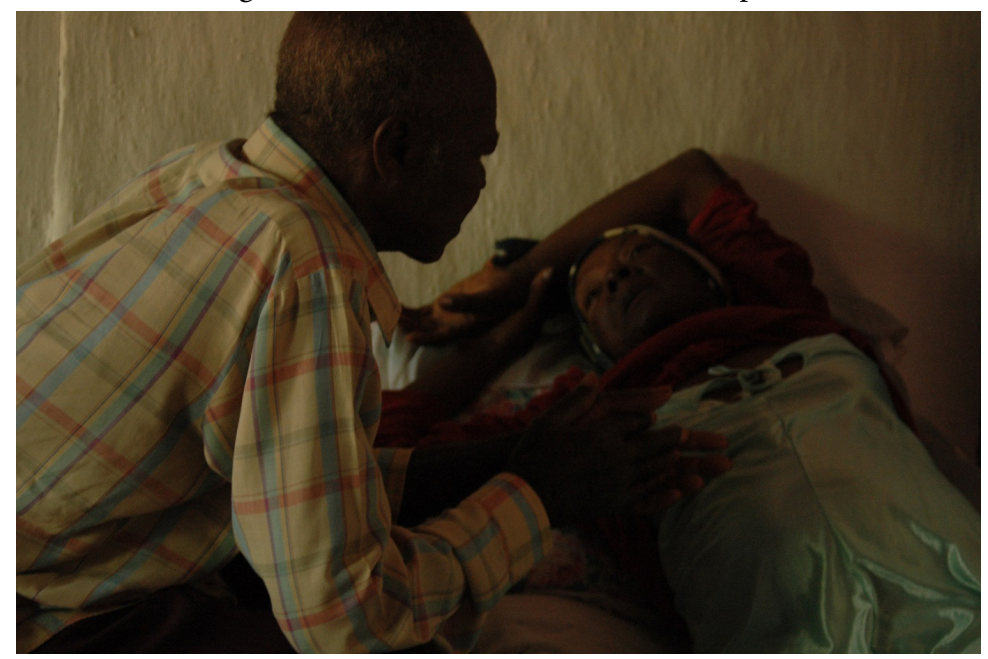

Fonte: Todas as fotografias são de minha autoria. Essa imagem data de dezembro de 2006. Grann e pastè Christ-Roi sabiam que eu a publicaria.

Fotografia 7 - A pausa, o cansaço, a espera.

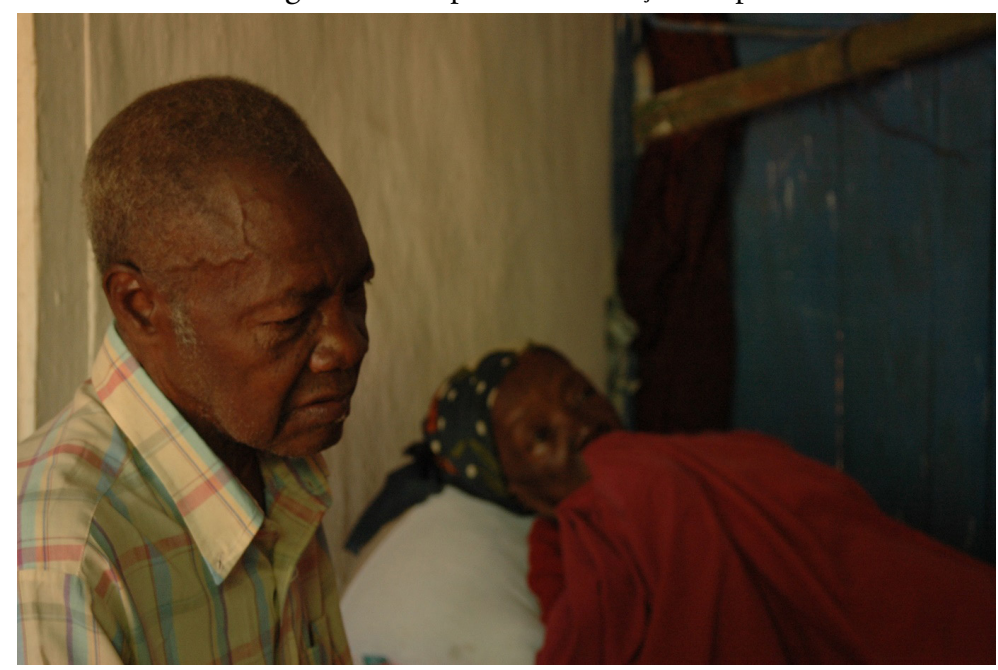

Fonte: Todas as fotografias são de minha autoria. Essa imagem data de dezembro de 2006. Grann e pastè Christ-Roi sabiam que eu a publicaria. 
Fotografia 8 - As visitas e Pastè Christ-Roi orando pela casa.

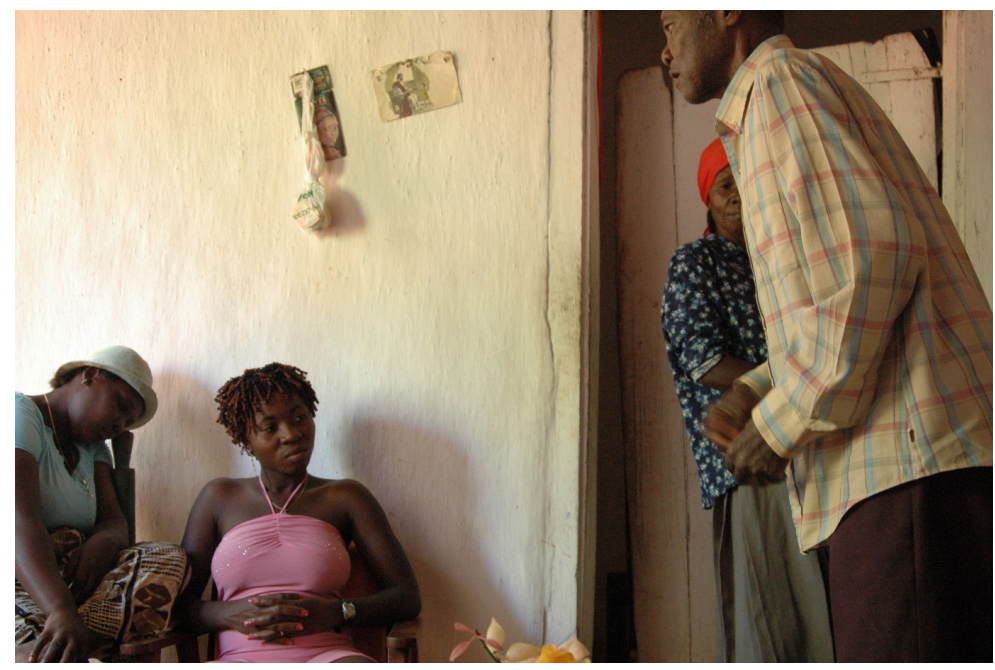

Fonte: Todas as fotografias são de minha autoria. Essa imagem data de dezembro de 2006. Grann e pastè Christ-Roi sabiam que eu a publicaria.

Fotografia 9 - Toque.

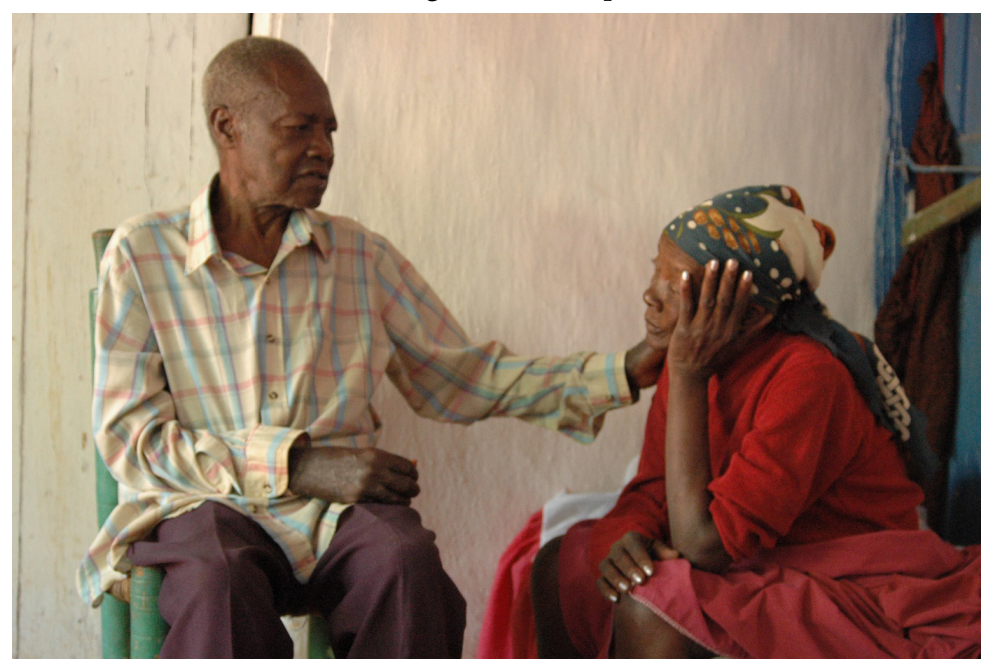

Fonte: Todas as fotografias são de minha autoria. Essa imagem data de dezembro de 2006. Grann e pastè Christ-Roi sabiam que eu a publicaria. 
Fotografia 10 - Lado a lado.

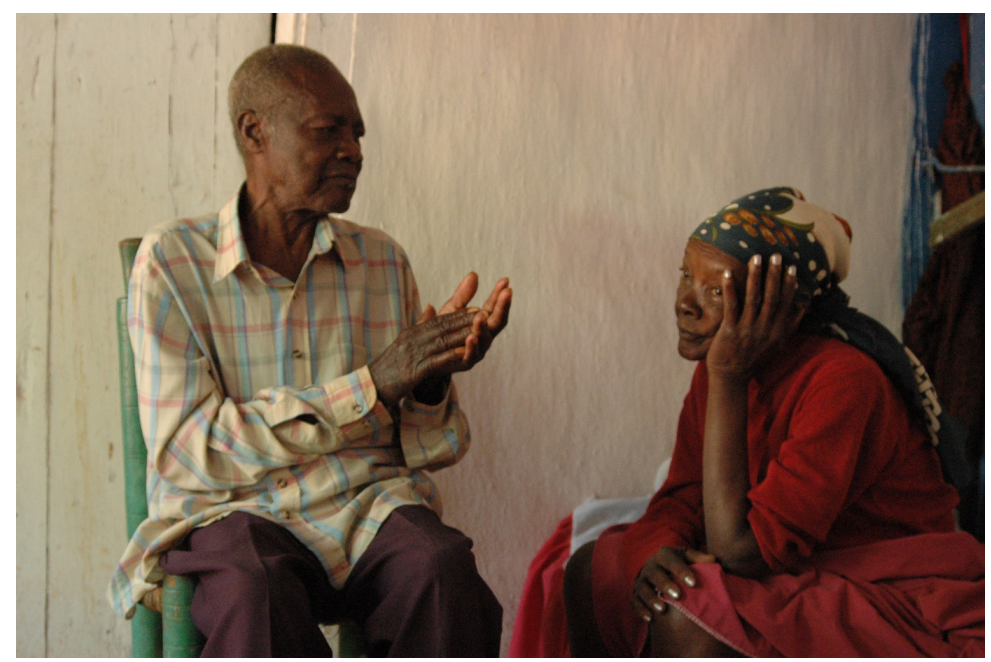

Fonte: Todas as fotografias são de minha autoria. Essa imagem data de dezembro de 2006. Grann e pastè Christ-Roi sabiam que eu a publicaria.

Recebido em: 20/12/2018

Aceito em: 20/12/2018 